\title{
ABSTRACT \\ HOW PISTACHIOS MAY FAVORABLY INFLUENCE AN INDIVIDUAL'S METABOLIC PROFILE AND RISK FOR CHRONIC DISEASES ASSOCIATED WITH INFLAMMATION
}

In the United States there is an increasing trend in chronic health conditions such as Diabetes Mellitus (DM), Hypertension (HTN) and Cardio Vascular Disease (CVD). One way of determining an individual's risk for developing these diseases is by evaluating their metabolic profile. Metabolic syndrome (MetS) is a term used to describe an unhealthy metabolic profile such as, elevated waist circumference, elevated triglycerides, high blood pressure and glucose intolerance. Studies have shown that nuts, such as pistachios, walnuts and almonds, can help reduce the risk of developing CVD and HTN due to their favorable fatty acid profile and nutrient dense composition. This parallel, controlled, randomized study evaluated the effects of daily consumption of $3 \mathrm{oz}$ of pistachios over an 8-week period on 12 subjects with MetS. No significant changes were detected in the variables assessed, Fasting Plasma Glucose, Total Cholesterol, Very Low Density Lipoprotein, Low Density Lipoprotein, Blood pressure, hs-CRP and High Density Lipoprotein. It is important to note that no negative changes were observed. This study supports previous research on pistachios and the claim that: although they are energy dense pistachios can be incorporated into the diet of a high risk subject such as an individual with MetS, without any harmful side effects such as elevated TC and LDL.

Mary Perez

August 2010 

HOW PISTACHIOS MAY FAVORABLY INFLUENCE AN INDIVIDUAL'S METABOLIC PROFILE AND RISK FOR CHRONIC DISEASES ASSOCIATED WITH

INFLAMMATION

\author{
by \\ Mary Perez
}

\begin{abstract}
A thesis
submitted in partial

fulfillment of the requirements for the degree of Master of Science in Food and Nutritional Sciences in the Jordan College of Agricultural Sciences and Technology California State University, Fresno
\end{abstract} August 2010 


\begin{abstract}
APPROVED
For the Department of Food Science and Nutrition:
\end{abstract}

We, the undersigned, certify that the thesis of the following student meets the required standards of scholarship, format, and style of the university and the student's graduate degree program for the awarding of the master's degree.

Mary Perez

Thesis Author

$\overline{\text { Lisa Herzig (Chair) } \quad \text { Food Science and Nutrition }}$

Gour Choudhury

Food Science and Nutrition

Mollie Smith

Food Science and Nutrition

For the University Graduate Committee:

Dean, Division of Graduate Studies 


\section{AUTHORIZATION FOR REPRODUCTION}

\section{OF MASTER'S THESIS}

$\mathrm{X} \quad$ I grant permission for the reproduction of this thesis in part or in its entirety without further authorization from me, on the condition that the person or agency requesting reproduction absorbs the cost and provides proper acknowledgment of authorship.

Permission to reproduce this thesis in part or in its entirety must be obtained from me.

Signature of thesis author: 


\section{ACKNOWLEDGMENTS}

I want to express my appreciation to everyone that contributed to the CSUFresno, Pistachio Health Research Project including but not limited to: Western Pistachio Association, Lisa Herzig PhD, Gour Choudhury PhD, Mollie Smith RD, Charles Morales NP, Lisa Walters NP, Paul Norwood MD, Sierra Endocrine staff and patients, and Cardiovascular Consultants staff and patients, and the Dietetics Students at CSUF that participated. Your efforts have made this study possible. 


\section{TABLE OF CONTENTS}

Page

LIST OF TABLES . . . . . . . . . . . . . . . . . . . . . vii

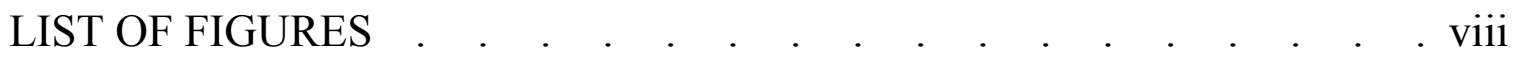

Chapter

1. INTRODUCTION . . . . . . . . . . . . . . . . . . . .

2. LITERATURE REVIEW . . . . . . . . . . . . . 7

Health Problem . . . . . . . . . . . . . . . 7

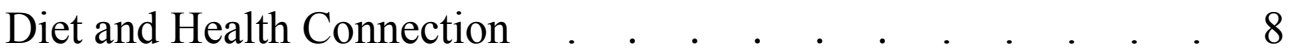

Nut and Health Relationship . . . . . . . . . . . . 9

Diet and Metabolic Syndrome . . . . . . . . . . . . . 13

Potential Pistachio Health Benefits . . . . . . . . . 14

3. METHODOLOGY . . . . . . . . . . . . . . . 18

Subject Recruitment. . . . . . . . . . . . . . 18

Subject Selection . . . . . . . . . . . . . . . . 18

Subject Criteria . . . . . . . . . . . . . . . 20

Experimental Design . . . . . . . . . . . . . 20

Dietary Intervention. . . . . . . . . . . . . . 21

Measurements . . . . . . . . . . . . . . . 22

Statistical Analysis and Interpretation. . . . . . . . . . . 24

4. RESULTS . . . . . . . . . . . . . . . . . 25

Lipid Panel .

Blood Pressure, Resting Metabolic Rate, FPG, and CRP . . 25

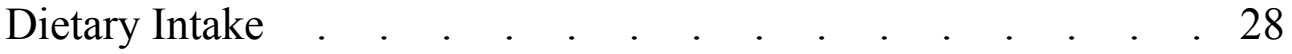


5. DISCUSSION . . . . . . . . . . . . . . . . . . . 29

Examination of Results . . . . . . . . . . . . . . . 29

Future Applications and Conclusions . . . . . . . . . . 31

REFERENCES . . . . . . . . . . . . . . . . . . . . . . 32

APPENDICES . . . . . . . . . . . . . . . . . . . . . . .

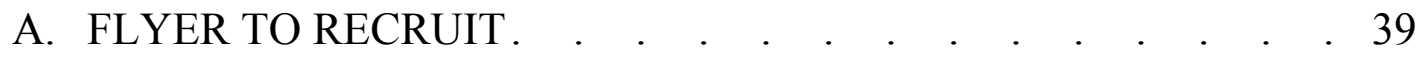

B. LETTER TO RECRUIT . . . . . . . . . . . . . . . . . 41

C. INFORMATION SESSION AGENDA . . . . . . . . . . . . 43

D. INITIAL DEMOGRAPHIC QUESTIONNAIRE . . • . . . . 45

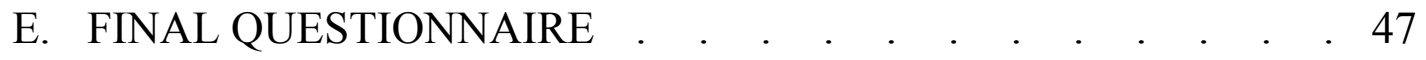

F. PROTOCOL FOR BLOOD DRAW . . . . . . . . . . . . . 49

G. QUESTIONS DURING BLOOD PRESSURE MEASUREMENT 53

H. PROTOCOL FOR BLOOD PRESSURE AND RESTING HEART

RATE. . . . . . . . . . . . . . . . . . 


\section{LIST OF TABLES}

\section{Table}

1. Nutrient composition of roasted unsalted almonds pistachios and raw English walnuts . . . . . . . . . . . . . . . 11

2. Characteristics at baseline for participants who completed study . . 19

3. Serum lipid effects of pistachios in subjects with MetS . . . . . 26

4. Blood pressure, resting heart rate, fasting plasma glucose and C-reactive protein effects of pistachios on subjects with MetS . . . . . 27

5. Analysis of food dairies of subjects with MetS and resting metabolic rates given in kcal . . . . . . . . . . . . . . 28 


\section{LIST OF FIGURES}

Figure

1. The effects of almonds on total cholesterol and low density lipoprotein levels . . . . . . . . . . . . . . . . 5

2. Fatty acid profile of nuts: almond, pistachios dry roasted unsalted, and raw English walnuts . . . . . . . . . . . . . . 10 


\section{Chapter 1}

\section{INTRODUCTION}

There is an increasing trend in chronic health conditions associated with poor eating habits (1). Chronic health conditions such as Diabetes Mellitus (DM) and Cardio Vascular Disease (CVD) are among the most common causes of disability and death in the United States $(1,2)$. The risk of developing these diseases is related to an individual's metabolic profile. The metabolic profile consists of the serum lipid and glucose levels which can be affected by diet (3). Metabolic syndrome (MetS) is a term used to describe an unhealthy metabolic profile (4). The definition according to the Adult Treatment Panel III guidelines consists of three out of the five following metabolic risk factors: fasting plasma glucose $(\mathrm{FPG}) \geq 110 \mathrm{mg} / \mathrm{dL}$, high density lipoprotein $(\mathrm{HDL})$ cholesterol $<40$ $\mathrm{mg} / \mathrm{dL}$ for men and $<50 \mathrm{mg} / \mathrm{dL}$ for women, triglycerides $(\mathrm{TG}) \geq 150 \mathrm{mg} / \mathrm{d}$, waist circumference $(\mathrm{WC})>40$ " or $102 \mathrm{~cm}$ for men and $>35$ "'or $88 \mathrm{~cm}$ for women, and/or blood pressure (BP) $\geq 130 \mathrm{mmHg}$ systolic or $\geq 85 \mathrm{mmHg}$ diastolic (5). Individuals diagnosed with this condition are at a twofold greater risk of developing CVD and a fivefold greater risk of developing DM $(5,6)$.

Currently $35 \%$ of the US population meets the criteria to be diagnosed with MetS (6). The costs associated with treating the diseases linked to MetS are enormous, for instance the annual cost of treating DM is estimated to be $\$ 174$ billion per year (7). The current health situation is growing worse as the number of Americans diagnosed with MetS continues to increase (6). Current recommendations for the treatment of MetS include pharmacotherapy, surgery, diet and lifestyle changes. 
Diet is a factor that has been shown to affect an individual's health profile such as the serum lipid panel. The serum lipid panel consists of the following: Total Cholesterol (TC), Low Density Lipoprotein (LDL), HDL and TG. Healthy fats such as: monounsaturated fats and omega-3 fatty acids can provide preventative protection against MetS, CVD and DM by altering the lipid panel $(1,3)$. Healthy fats can have an influence on the lipid panel by changing the composition of certain lipoproteins such as LDL and HDL involved in fat transportation. For example, high monounsaturated fat diets ( $\geq 35 \%$ of total energy from fat) have been shown to affect lipoprotein levels more favorably compared to a low fat diet (less than $20 \%$ of total calorie intake from fat) $(8,9)$. In a parallel study design conducted by Pelkman and colleagues, 53 obese subjects were randomly assigned to either a low fat (20\% energy from fat) or moderate fat ( $35 \%$ of energy from monounsaturated fat) weight loss diet throughout a 10-week period. The initial 6-weeks of the study consisted of a weight loss diet and the last 4-weeks weight maintenance. The study found that both diets decreased TC and LDL, however the low fat diet decreased HDL (the good cholesterol) by $12 \%$. In addition, during the weight maintenance period TG rebounded to baseline levels. The moderate fat diet (from monounsaturated fat) on the other hand did not increase TG during weight maintenance period (9). Mediterranean countries such as Greece and Croatia experience lower incidences of heart disease because of their popular high monounsaturated / low unsaturated fat diet $(1,10)$. Low fat diets have also been shown to improve the metabolic profile by reducing TC and LDL, however TG have been shown to increase.

Almonds, macadamia nuts and pistachios are a good source of monounsaturated fatty acids and are a large component of the Mediterranean diet. The Mediterranean diet will be further explained in the literature review 
subsection entitled: Diet and Health Connection. The Mediterranean Diet emphasizes a daily consumption of whole grains, fruits, vegetables, olive oil, and nuts. Nuts such as almonds, and walnuts have been shown to decrease the risk of coronary heart disease (CHD) by as much as $50 \%(3,11)$. The most commonly researched nuts are almonds and walnuts. Increased consumption of these nuts is associated with decreased TC and LDL $(3,11,12)$ As previously mentioned, elevated levels of TC and LDL are associated with increased risk for CVD. HDL can prevent CVD by transporting cholesterol from the blood to the liver to be excreted. There has been little success in terms of the effect that almonds have had on increasing HDL, however pistachios have been shown to increase HDL (12). It should be noted that not all studies on pistachios and health have seen an increase in HDL when pistachios were administered (13).

The Mediterranean diet is also low in saturated fat. Saturated fats such as myristic acid (C14:0), and palmitic acid (C16:0), have been shown to have the opposite effect, that is they increase TC and LDL (14-16). Nuts such as pistachios, almonds, and walnuts are low in saturated fat. Insulin sensitivity can also be affected by a low saturated fat diet. Saturated fats affect the levels of certain cytokines such as adiponectin. Cytokines are involved in cell to cell signaling. Low adiponectin levels are related to reduced cell insulin sensitivity and inflammation $(15,16)$. Adiponectin stimulates synthesis of Glucose Transporter 4 (GLUT4) gene expression, thereby increasing glucose uptake by the cells. In addition, it reduces the production of certain pro-inflammatory hormones such as Tumor Necrosis Factor- $\alpha$ (TNF- $\alpha$ ). Plasma adiponectin levels are lower in individuals with CVD and DM.

Almonds produce more favorable effects when compared to a high monounsaturated fat diet alone, suggesting that there is more to the nut effect then 
their fatty acid profile. In a randomized, parallel, controlled study design conducted by Spiller and colleagues, 45 hyperlipidemic men were randomly split into three different groups with mean cholesterol levels of $251 \pm 30 \mathrm{mg} / \mathrm{dL}$. The three groups were assigned a different 4-week diet, which consisted of one of the following: almonds (100 g/day), olive oil (48 g/day) and butter and cheese (control) diet. The researchers found that the almond diet decreased TC and LDL more favorably then compared to the other diets (17). The results of the study follow (refer to Figure 1): TC (almond group: $222 \pm 28 \mathrm{mg} / \mathrm{dL}$, olive oil group: $240 \pm 27 \mathrm{mg} / \mathrm{dL}$, control group: $263 \pm 42 \mathrm{mg} / \mathrm{dL} ; \mathrm{p}=0.001$ ) and LDL-C (almond group: $141 \pm 25 \mathrm{mg} / \mathrm{dL}$, olive oil group: $157 \pm 21 \mathrm{mg} / \mathrm{dL}$, control group: $174 \pm 39$ $\mathrm{mg} / \mathrm{dL} ; \mathrm{p}=0.001$ ), but no significant changes in HDL-C, TG, or TC/HDL levels. Spiller and colleagues note that the increased consumption of plant food and decreased consumption of animal food may have contributed to the results of the study (17). Pistachios have a similar fatty acid profile to almonds, which is predominately monounsaturated fatty acid. In addition, pistachios have a greater antioxidant capacity.

The antioxidant capacity of nuts such as almonds, pecans and pistachios contributes to their beneficial qualities. Pistachios rank among the highest in nuts in terms of antioxidant capacity. The green color of pistachios is attributed to lutein which is a phytochemical also known as a plant antioxidant (18). The beneficial properties of antioxidants have been shown to reduce inflammation which can be measured by $\mathrm{C}$ - Reactive Protein (CRP). CRP is one of the inflammatory acute phase response proteins that have been associated with the progression of atherosclerosis and myocardial infarction (MI). High sensitivity CRP (hs-CRP) is used to measure small increases in CRP and is directly related to CVD risk (19). MetS is linked to higher levels of hs-CRP (20). 


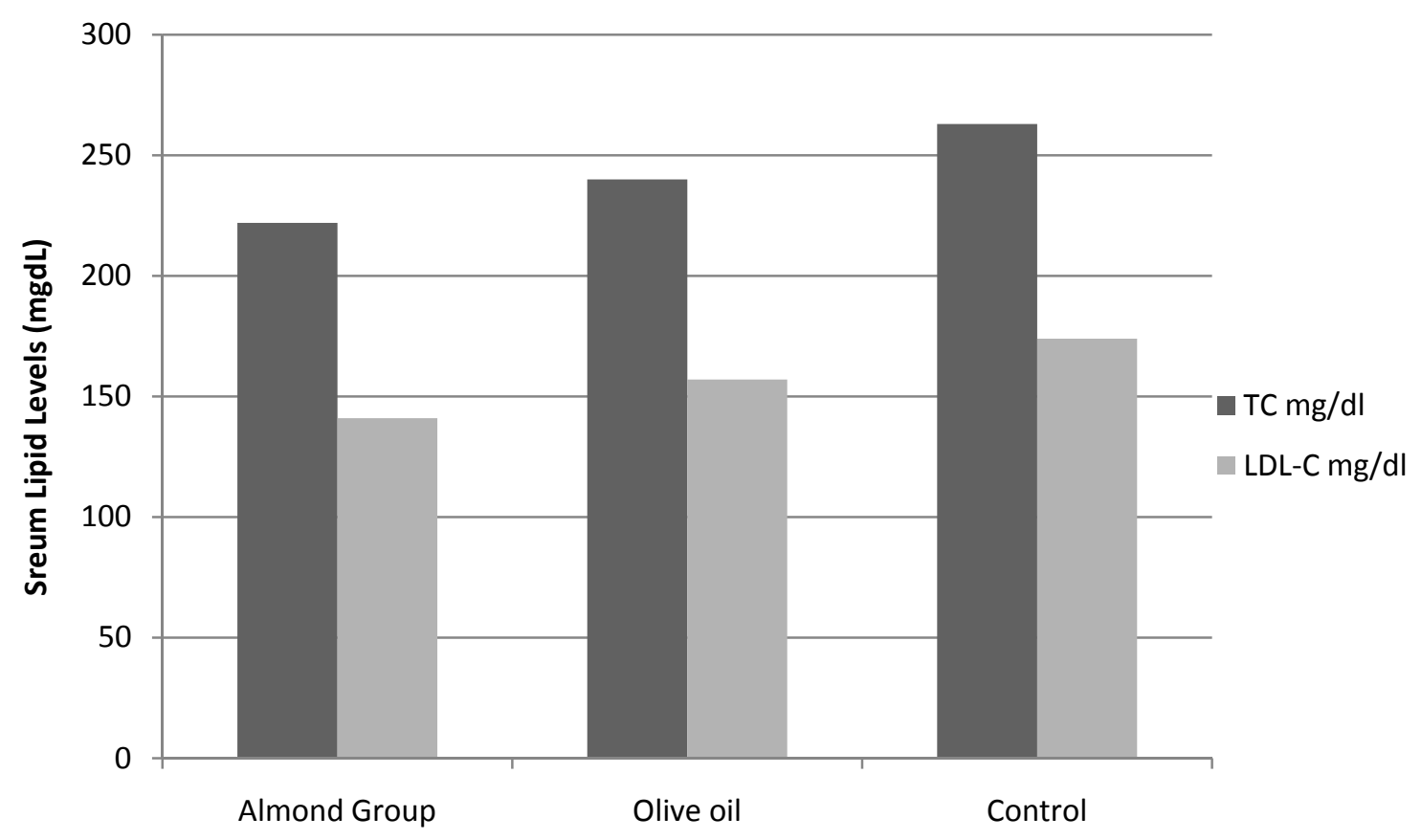

Figure 1 . The effects of almonds on total cholesterol and low density lipoprotein levels (17).

The mechanism by which antioxidants prevent or reduce inflammation is related to the stabilization of free radicals. In particular, antioxidants prevent the oxidation of LDL. Oxidized LDL promotes formation of plaque in the arteries leading to atherosclerosis (21). The type of dietary fat consumed such as omega 3 fatty acids and monounsaturated fats can also prevent the formation of proinflammatory markers $(16,22)$. Pro-inflammatory markers such as TNF- $\alpha$ stimulate the production of CRP (19). Oleic acid a monounsaturated fatty acid which is found in pistachios has been shown to reduce CRP when consumed in modest amounts (20\% of total caloric intake) (22). Nuts such as pistachios and almonds are a good source of oleic acid (23).

Even though pistachios possess a similar fatty acid profile to almonds, it has not been as thoroughly examined. The research conducted by Spiller, Jenkins, 
Peterson, and colleagues has shown that nuts such as almonds, walnuts and pistachios can produce desirable changes on health by improving metabolic risk factors such as decreasing LDL and increasing HDL. Blood Pressure (BP) is an additional symptom included in the clustering of symptoms for MetS. Elevated BP is considered even when controlled with medication. This study will not only look at the lipid profile related to MetS, but BP as well.

As previously mentioned, MetS is characterized by a group of metabolic risk factors: BP, HDL, FPG, TG. Evaluating the effect produced by increased pistachio consumption will increase current knowledge regarding the mechanism by which health risks are reduced The objectives of this study were to determine the effect of substituting $3 \mathrm{oz}$ ( $20 \%$ caloric intake) unsalted, roasted shelled pistachio nuts ( $3 \mathrm{oz} /$ day) on high risk individuals diagnosed with MetS, DM and hypertension (HTN). This population continues to increase and it is of concern due to the risk for other health complications (4). The variables we concentrated on included: the lipid health panel (LDL, HDL, TG, TC), BP, Resting Heart Rate (RHR), FPG levels and hs-CRP a bio-marker of inflammation. The importance of these variables will be discussed in the Literature Review. 


\section{Chapter 2}

\section{LITERATURE REVIEW}

\section{Health Problem}

MetS is characterized by a group of metabolic risk factors that includes

three or the more of the following five criteria: fasting plasma glucose $\geq 110$ $\mathrm{mg} / \mathrm{dL}$, high density lipoprotein (HDL) cholesterol $<40 \mathrm{mg} / \mathrm{dL}$ for men and $<50$ $\mathrm{mg} / \mathrm{dL}$ for women, triglycerides (TG) $\geq 150 \mathrm{mg} / \mathrm{d}$, waist circumference (WC) $>40$ " or $102 \mathrm{~cm}$ for men and $>35$ "or $88 \mathrm{~cm}$ for women, and/or blood pressure (BP) $\geq 130$ $\mathrm{mmHg}$ systolic or $\geq 85 \mathrm{mmHg}$ diastolic (6). Individuals diagnosed with MetS are at a twofold greater risk of developing CVD and fivefold greater risk of developing DM (5). CVD is the leading cause of death in the United States (2). According to the Center of Disease Control, 700,000 people die of heart disease in the U.S. each year, which constitutes $29 \%$ of the total deaths. These diseases incur huge expenses for the government. Heart related problems have cost the United States more than $\$ 400$ billion in health care and lost productivity for the year 2006 (2).

$\mathrm{DM}$ is another major debilitating disease and it is on the rise like MetS (4). The risk for all cause mortality associated with MetS is more closely linked to DM (24). Currently $35 \%$ of the US population meets the criteria to be diagnosed with MetS. Risk factors for MetS include: age, gender, lower socioeconomic status, and ethnicity (24). These common and costly diseases can be prevented through diet. Diet has been implicated in the reduction of these chronic health conditions through the improvement of the health profile such as, serum lipid levels and FPG levels (25) Diets that are low in saturated fat and moderate in unsaturated fats such 
as the Mediterranean diet have been particularly associated with lower incidences of chronic diseases, such as DM and CVD.

\section{Diet and Health Connection}

Mediterranean countries experience lower incidences of heart disease and death $(26,27)$. The Mediterranean diet is recognized as an important factor behind this trend. This diet consists primarily of fresh fruits and vegetables, legumes, cereals, olive oil and nuts (27). Despite its high fat content reduced incidences of heart disease are associated with the Mediterranean diet. In the Seguimiento Universidad de Navarra (SUN) prospective cohort study MetS incidence was inversely related to the Mediterranean diet. In the SUN study individuals who had consumed this type of diet had a reduced incidence of MetS (27). The Mediterranean diet has less saturated fat and more monounsaturated fat up to $40 \%$ of calories per day may be from fat. The diet consists of a daily consumption of fruits, vegetables, bread, grains, potatoes, beans, nuts seeds and olive oil. In addition, the diet limits intake of meats (twice a week) especially red meat (12 to 16 oz per month) (26).

Diet modifications that include incorporating more monounsaturated fats and reducing saturated fats decrease the incidence of heart disease by improving lipid and insulin profiles $(10,28)$. A randomized cross over trial conducted by Garg and colleagues revealed that a high monounsaturated fat diet versus a lower fat high carbohydrate diet resulted in lower FPG levels, reduced insulin requirements, lower levels of plasma TG and Very Low Density Lipoprotein (VLDL) cholesterol, and higher levels of HDL in patients with DM. The study defined a high-carbohydrate low fat diet as $25 \%$ of the energy from fat and $60 \%$ of total energy intake from carbohydrates $(47 \%$ of the total energy was in the form of 
complex carbohydrates); in the high-monounsaturated-fat diet, $50 \%$ of calorie intake was from fat $33 \%$ of the total energy in the form of monounsaturated fatty acids) and 35\% of total calorie intake in the form of carbohydrates (29). Another study conducted by Berry and colleagues showed that a high monounsaturated fat diet can have more favorable effects on TC and LDL, than a low fat diet (10). In addition, in a more recent 6-month study conducted by Due and colleagues, the study showed that a diet high in monounsaturated fats (35-45\% of total energy from fat per day, of which $>20 \%$ monounsaturated fats) was found to be more beneficial than the recommended low fat diet (20 to 30\% of energy) on glucose tolerance and insulin resistance (28).

Almonds and pistachios are a good source of monounsaturated fat, in particular the fatty acid oleic acid. Consuming nuts such as almonds, walnuts and pistachios greater than 5 times a week was associated with the lowest risk of coronary artery disease $(\mathrm{CAD})(3,10)$. However, nuts such as almonds produced more favorable lipid altering results when compared with a high monounsaturated fat (Oleic) diet alone, suggesting that there is more to the nut effect then the fatty acid profile (17).

\section{Nut and Health Relationship}

Nuts such as walnuts, almonds and pistachios possess valuable nutrients such as fiber, unsaturated fatty acids, phytosterols and phytochemicals (refer to Table 1). The chemical composition of nuts such as almonds, walnuts and pistachios has been shown to decrease metabolic risk factors such as lipid levels, blood pressure and fasting glucose levels. The favorable fatty acid profile of nuts partly explains their protective effects (refer to Figure 2). An epidemiologic study, the Adventist Health Study, has shown that consumption of $5 \mathrm{oz}$ of nuts per week 
is associated with a $30 \%$ to $50 \%$ decrease in risk for CHD (3). In this study, the frequency of nut consumption was correlated to relative risks of CHD. Along with reduced CHD rates, improved glucose levels have also been detected in DM patients $(22,29)$ : For instance, in a study conducted by Garg that compared a high mono-unsaturated fat diet and a high carbohydrate diet, the high monounsaturated diet yielded lower glucose levels (29).

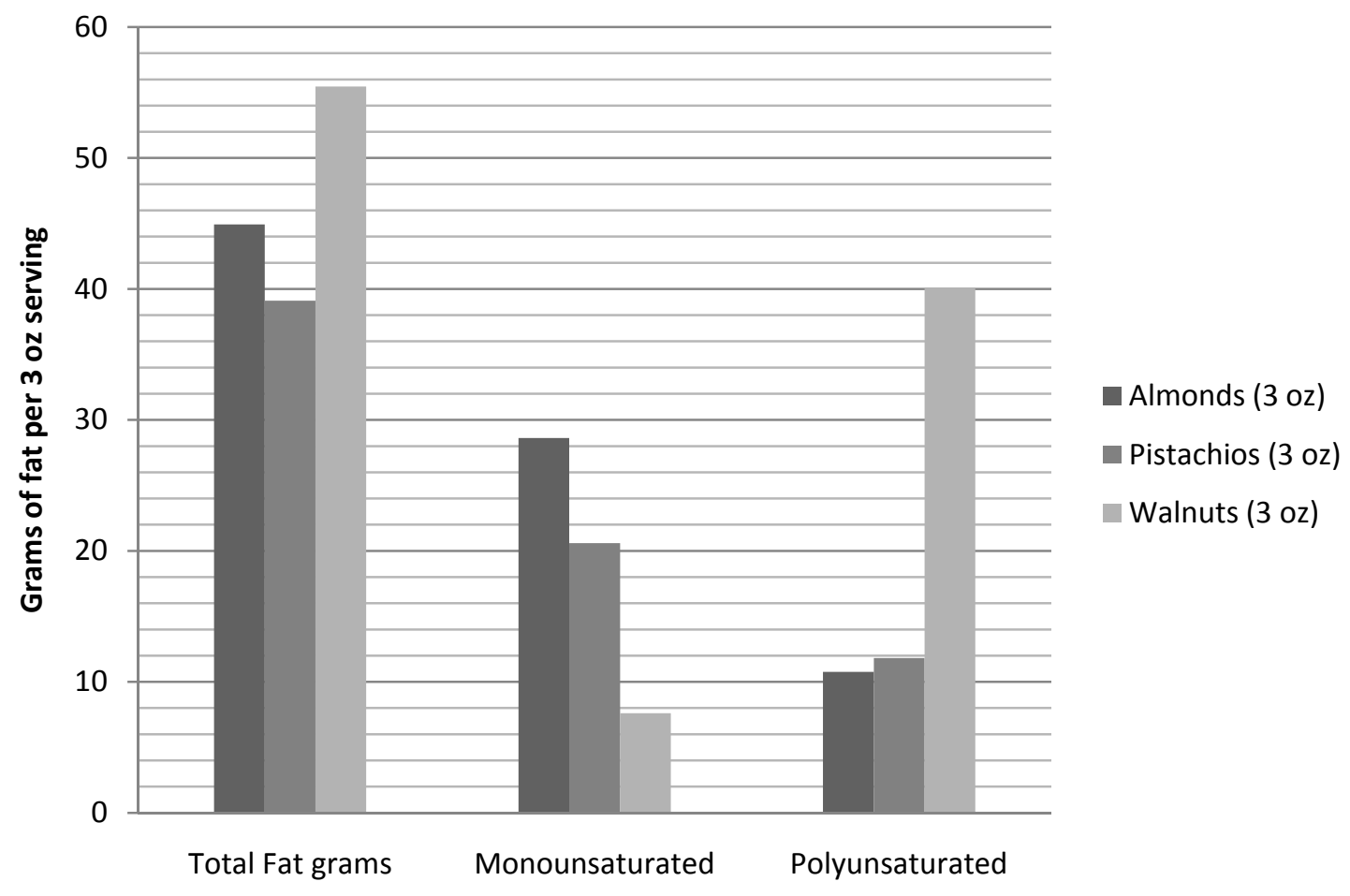

Figure 2. Fatty acid profile of nuts: almond, pistachios dry roasted unsalted, and raw English walnuts (26).

The favorable fatty acid profile of nuts such as almonds (refer to Figure 2) have also been shown to more effectively reduce plasma glucose levels compared to a high carbohydrate diet (29). Glucose intolerance is directly related to DM. Nuts such as almonds and pistachios are an ideal snack for diabetics. They are low in carbohydrates, nutrient dense, and good sources of fiber and protein (refer to 
Table 1). Despite the high energy content of nuts, nut consumption has not been linked to increased caloric intake or weight gain $(30,31)$. In fact, frequent peanut and tree nut consumption has been associated with lower BMI status. However, another study conducted by Sabate and colleagues, found that when subjects were given peanuts or tree nuts to consume freely without dietary guidance, weight gain may be observed (32). Weight and BMI are used as part of the criteria to diagnose individuals with MetS. Long term studies on weight gain and nut consumption were limited to epidemiological studies $(32,33)$. The study conducted by Sabate and colleagues concluded that the plausible explanation as to why no weight gain is observed with increased nut consumption is partially due to an increased satiety and fiber intake. Fiber slows the digestion of food and the release of sugar into the blood $(30,32)$.

\section{Table 1.}

Nutrient composition of roasted unsalted almonds, pistachios and raw English walnuts (23)

\begin{tabular}{|c|c|c|c|}
\hline & Almonds & Pistachios & Walnuts \\
\hline & $(3.0 \mathrm{oz})$ & $(3.0 \mathrm{oz})$ & $(3.0 \mathrm{oz})$ \\
\hline Energy (kcal) & 508 & 486 & 556 \\
\hline Total Fat g & 44.93 & 39.1 & 55.46 \\
\hline Monounsaturated Fat $g$ & 28.626 & 20.596 & 7.598 \\
\hline Polyunsaturated Fat g & 10.758 & 11.821 & 40.121 \\
\hline Fiber g & 10 & 8.8 & 5.7 \\
\hline Potassium mg & 634 & 886 & 375 \\
\hline Phytosterols mg & 100 & 182 & 61 \\
\hline Arginine $\mathrm{g}$ & 2.179 & 1.793 & 1.937 \\
\hline
\end{tabular}


Almonds and pistachios' positive effect is dose dependent. A study conducted by Jenkins and colleagues evaluated the dose response of almonds on hypercholesterolemia patients. The results of the study indicate that consuming 3 oz of almonds a day resulted in greater improvements of CHD risk factors such as LDL, and TC, when compared to a smaller $1.5 \mathrm{oz}$ dose (25). This same trend in dosage response was observed in another study conducted by Penn State University. The study examined pistachios and the dosage response and found that $3 \mathrm{oz}$ of pistachios yielded more favorable results compared to $1.5 \mathrm{oz}$ : for example LDL levels decreased $12 \%$ when given $3 \mathrm{oz}$ and $9 \%$ when given $1.5 \mathrm{oz}$ pistachios (34).

Pistachios have more kernels per servings versus almonds. 3 oz of almonds constitutes 69 kernels and $489 \mathrm{kcal}$. On the other hand, $3 \mathrm{oz}$ of pistachios constitutes 147 kernels and $480 \mathrm{kcal}$ (refer to Figure 2) (23). In addition, $1 \mathrm{oz}$ of pistachios has twice the amount of kernels versus $1 \mathrm{oz}$ of almonds with an equal amount of calories. The $3 \mathrm{oz}$ dose constitutes approximately $20 \%$ of the recommended daily caloric intake of fat.

Salted nuts such as almonds have been shown to yield similar results as raw unsalted almonds (35). In a study conducted by Spiller and colleagues different almond products were evaluated to determine whether $100 \mathrm{~g}$ of the following, raw almonds, salted roasted almonds and unsalted roasted almond butter could favorably affect the metabolic profile of 45 hypercholesterolemic males and females. The variables of concern in this study included, TC, LDL, HDL and TG. The results of the study indicate that the raw form of almonds produced the most favorable effect by lowering TC (-7\%) and LDL (-12\%). All forms of the almond product decreased TC and LDL, except the almond butter group did not decrease 
TC. In addition, no significant changes were seen in HDL or TG, except for the almond butter group, HDL increased by $+8 \%$ (35).

Many types of tree nuts such as almonds, pistachios and walnuts are a good source of protein. Amino acids make up total protein. Pistachios are particularly high in the amino acid arginine (1.793 g per 3oz pistachios) (23). Arginine is a precursor of the endothelium-derived relaxing factor, nitric oxide (NO) (36). NO is a vasodilator that can inhibit platelet aggregation and adhesion. Inhibiting platelet aggregation and adhesion can help in preventing atherosclerosis and blood clots. MetS can increase overall risk for atherosclerosis and blood clots.

Only a small amount of research has been concentrated on pistachios. The research that has been conducted on pistachios looks at the dosage response of pistachios on TC and LDL $(13,31,34)$. Pistachios are a good source of nutrients such as but not limited to: potassium and lutein, therefore they are worth studying (refer to Table 1).

\section{Diet and Metabolic Syndrome}

There are few studies that focused on nuts and their effects on MetS.

Several studies look at MetS and salt sensitivity, as well as MetS and consumption of walnuts and cashews. This group is difficult to evaluate because they are a high risk group generally on multi-pharmacotherapy. Pharmacotherapy is treatment of a disease with medicine. Multi-pharmacotherapy is the use of several medications to treat different ailments. In a randomized, parallel, controlled study conducted by Mukudden and colleagues, the effects of a high walnut and high unsalted cashew nut diet ( $20 \%$ of total energy from nuts) did not observe any favorable effects on the metabolic profile. The researchers attribute this finding to their subject's weight maintenance and the short duration of the study (8-weeks). The researchers 
hypothesized that if the diet were longer an effect on BP may have been observed (37).

Body composition plays a significant role in the pathogenesis of MetS, however it does not act alone. One of the criteria associated with the diagnosis of MetS is obesity which may be assessed by using either BMI or Waist Circumference (WC). It is defined as a BMI greater than $29.9 \mathrm{~kg} / \mathrm{m}^{2}$ and a WC greater than 35 " for women and 40 " for men. Interventions aimed at preventing or reversing MetS include a 5-10 \% weight loss. However many other alternatives exist in the prevention and intervention of MetS that include: pharmacotherapy, a low carbohydrate diet or the Mediterranean diet.

Eliminating certain foods such as saturated fats found in tropical oils, animal fats, and partially-hydrogenated fats can also lower TC and LDL. Pistachios are low in saturated fat and they do not contain hydrogenated fats. During this study weight maintenance was encouraged through the use of a calorie controlled diet. This will be further discussed in the methodology section.

\section{Potential Pistachio Health Benefits}

Previous research has been conducted on pistachios evaluating the effects of adding pistachios to the diet of hypercholesterolemic individuals; however little research has been identified looking at participants diagnosed with MetS. The Penn State Pistachio study demonstrated that pistachios lower metabolic risk factors such as: TC, and LDL in a dose dependent manner. The following two dosages of pistachios were used in the study: 1 serving per day ( $10 \%$ of total energy from pistachio) and 2 servings per day (20\% of total energy from pistachios). The larger and smaller dosage results listed respectively reduced TC 
by $-8 \%$ and $-1 \%$, and LDL by $-11.6 \%$ and $-3 \%$ (34). In addition, pistachios have been shown to increase HDL by $2.3 \mathrm{mg} / \mathrm{dL}(\mathrm{p}=0.02)$ (13).

Sheridan and colleagues' research on pistachios has shown more success with increasing HDL as compared to Spiller and colleagues' research on almonds, which did not show any significant increases in $\operatorname{HDL}(13,17)$. The validity of the results may be disputed based on the number of participants used and the length of the study (i.e. 4-weeks). HDL levels are inversely related to CHD rates (38). The Penn State Study found that pistachios improved total cholesterol/HDL ratio in patients with hypercholesterolemia (34). It should be noted that total cholesterol/HDL ratio is a superior measure of CHD risk as compared with either total cholesterol or LDL cholesterol levels (39). The change in TC, LDL and HDL, partly describes the mechanism by which pistachios reduce CVD fatalities. HDL cholesterol transports excess fat to the liver to be excreted. Low levels of HDL are associated with higher incidence of CVD (Men $\leq 40 \mathrm{mg} / \mathrm{dL}$ and Women $\leq 50$ $\mathrm{mg} / \mathrm{dL})(38)$.

Pistachios hold unique qualities that place them among the top nuts along with pecans and walnuts in terms of antioxidant capacity (TAC) $(18,40)$. In a study conducted by Kornsteiner the TAC values for several nuts were calculated, pecans $(179 \mu \mathrm{mol} \mathrm{TAC} / \mathrm{g})$, pistachios $(80 \mu \mathrm{mol} \mathrm{TAC} / \mathrm{g})$ and walnuts $(135 \mu \mathrm{mol}$ $\mathrm{TAC} / \mathrm{g}$ ). Kornsteiner notes that the results of the TAC measurement may vary according to the source and quality of the nuts used (18). Pistachios, unlike almonds and walnuts have larger quantities of lutein, an antioxidant, and potassium, an electrolyte (23).

Potassium has been shown to help with HTN (41). It is an electrolyte involved in water homeostasis. The amount of potassium $\left(\mathrm{K}^{+}\right)$in the pistachios used in this study is $1064 \mathrm{mg}$ per $3 \mathrm{oz}$. This nutrient composition analysis was 
provided by the Western Pistachio Association. The recommended dietary intake of potassium for men and women over the age of 18 is 2,000 $\mathrm{mg}$. Potassium has been shown to decrease blood pressure and the risk for CVD (42).

The green color of pistachios is primarily attributed to lutein, an antioxidant. The mechanism by which pistachios and tree nuts improve health profiles is not completely understood nor has it been adequately studied according to researchers including Sheridan, Edwards, Gebauer and colleagues $(13,31,34)$. This study is the first to look at the effects of pistachio consumption on the health profile of participants diagnosed with MetS. The current understanding of this mechanism suggests that it lowers incidences of heart disease by improving serum lipid level profiles and decreasing serum lipid oxidation.

Decreasing lipid oxidation, in particular LDL cholesterol oxidation, by means of increasing serum antioxidant capacities contributes to the favorable changes seen in participant health profiles. Antioxidant concentration in the blood is inversely related to the inflammatory marker hs-CRP (43). Levels of CRP, an inflammatory acute stress response protein mediated by the liver, rise in response to trauma and infection representing inflammation. A small increase in CRP is measured by hs-CRP $(19,44)$. A small elevation is CRP is associated with MetS, cell damage, and atherosclerosis $(44,45)$. Antioxidants have been shown to provide preventative protection against inflammation, but the properties and the mechanism responsible for producing such an effect has not been established (46).

The proposed study intended to further evaluate unsalted pistachios effect on the health of individuals diagnosed with MetS. The variables of concern in this study included: TC, HDL, LDL, BP, FPG, TG, hs-CRP and changes in CRP indicating inflammatory status. The increasing American trends in obesity and DM display the need for resolutions. Diet is the primary prevention strategy and 
adding pistachios to a diet can produce desirable results such as decreasing inflammation. We hypothesized that the study would support pistachios claim to be a delicious snack and fat alternative for high risk patients such as those with MetS. 


\section{Chapter 3}

\section{METHODOLOGY}

\section{$\underline{\text { Subject Recruitment }}$}

The subject recruitment process occurred three months prior to the study. Flyers (refer to Appendix A) were used to recruit participants. Flyers were distributed at the three local participating clinics: Sierra Endocrine, Dr. Norwood's Office and Cardiovascular Consultants Heart Center (CVC). In addition, a newsletter (refer to Appendix B) was distributed by mail to patients of CVC. Potential participants contacted us through email or by phone in response to the flyer. Those interested in the study received an invitation to attend an Informational Session (IFS). Three informational sessions were conducted to help recruit potential participants. The agenda for the informational sessions is outlined in Appendix C.

During the IFS, potential participants were informed of the study duration, participant obligations, and necessary prerequisites. The study required that participants enjoy pistachios, are non-smokers and are free of tree nut allergies. Those who decided to enroll and meet the screening criteria were asked to fill out an authorization and privacy disclosure that allows us to review their medical charts (see Appendix C for full IFS agenda and protocol).

\section{$\underline{\text { Subject Selection }}$}

The experiment included a total of 16 non-smoking participants, however only 12 of the 16 participants initially assessed completed the study. All of the subjects met the criteria for the condition MetS. Another selection criteria required 
was that the participant's weight have been stable (by $2.5 \mathrm{~kg}$ ) during the last 3 months.

The three local Fresno physician offices that participated in the study were: Sierra Endocrine, Dr. Norwood's Office and CVC. Although three clinics participated in the study all of the participants came from Sierra Endocrine and CVC. Of the potential participants screened 16 completed the $1^{\text {st }}$ health assessment but only 12 completed the study. Of the 12 participant's data, 2 were excluded from results and analysis, because the participant failed to adhere to study expectations (consuming pistachios daily or failed to fast during blood assessment).

The demographic information that was collected from the participants included: age, gender, exercise habits, supplement use, alcohol and smoking habits (refer to Table 2 and Appendix D). Exercise habits were determined by the number of hours spent exercising per week. This information was used as a reference during statistical analyses of results. Participants excluded from study were those who made recent changes in their lifestyle and/or medications. In addition, participants with thyroid conditions or other serious health conditions such as a hip fracture were excluded because of the influence it has on the metabolic rate.

\section{Table 2.}

Characteristics at baseline for participants who completed study

\begin{tabular}{|lcc|} 
& Pistachio Group $(\mathrm{n}=5)$ & Control Group $(\mathrm{n}=5)$ \\
Variables & Mean & Mean \\
\hline women $/$ men & $2 / 3$ & $2 / 3$ \\
age $(\mathrm{yrs})$ & 60.8 & 60.5 \\
BMI $\left(\mathrm{g} / \mathrm{m}^{2)}\right.$ & 32.16 & 32.78 \\
RMR $(\mathrm{kcal})$ & 2258 & 2302 \\
\hline
\end{tabular}




\section{$\underline{\text { Subject Criteria }}$}

Medications were not excluded from the study such as, beta blockers, thiazide diuretics, blood pressure medications and oral hypoglycemic agents: However, participants were instructed to notify us of any changes in medications. Physicians and participating practitioners agreed to maintain the same dose and type of medication for each participant throughout the duration of the study unless recommended otherwise. Any changes made were noted by the participant in the provided supplemental handbook and during final health assessment (refer to final questionnaire Appendix E). Of the participants that completed the study, 2 changed their medication dosage during the study. Participants with regular medication regimens were selectively recruited to study by physicians. In addition, we excluded subjects from the study with the following conditions and/or habits: renal or liver disease, history of tree nut allergies, cigarettes smokers and those who dislike pistachios.

\section{Experimental Design}

The selected experimental design was a randomized, controlled, parallel study. The study consisted of two separate participant groups each administered a different treatment in parallel. Group 1 was administered $3 \mathrm{oz}$ of unsalted pistachios. Group 2 served as the control and did not receive any pistachios. The 16 participants were grouped according to gender, age, and weight. After being split into subgroups the participants were assigned to one of the two different sections of the study randomly by using a table of random numbers: 8 participants per group. In addition, all groups were instructed to follow a calorie controlled diet according to the recommendations from the AHA (10) (please refer to Dietary Intervention for more detailed description). 
The duration of the treatment and the control was 8-weeks. A 3-month screening period was used to identify potential participants. The screening period included: collecting non smoking participants and their demographics (refer to Subject Selection section). The information collected from the participants included: age, gender, ethnicity, and lifestyle habits (refer to patient questionnaire Appendix D and Table 2).

\section{Dietary Intervention}

All participants received dietary consultation regarding serving portions and sizes (2010 CalorieKing Calorie, Fat \& Carbohydrate Counter by Allan Borushek). The purpose of the Calorie King book was to aid in teaching participants calorie counting and serving sizes so they could conduct their food recall more accurately. In addition, participants were instructed to substitute pistachio nuts for other fats such as olive oil, butter, margarine and cream cheese during the pistachio trial to ensure that all groups received equal amounts of fat in their diet. Participants were also instructed to control calorie intake and fat intake. Calculated caloric intake could deviate by $\pm 200 \mathrm{kcal}$. Calorie needs were calculated using an indirect calorimeter Reevue by Korr and the 1.3 Activity Factor (AF). The AF of 1.3 was used based on the subject's light physical activity level. Fat intake was adjusted to $20 \%$ of calorie needs according to AHA guidelines. The nutritional facts of the pistachios were given to participants, so that they can take into account the extra fat from the pistachios. The education was overseen by a Registered Dietitian graduate student Michelle Carrick. Participants were instructed not to consume any other nuts or nut products 2-weeks prior to initiation of the study and throughout the entire length of the study. 
Participants were introduced to a calorie controlled diet and Calorie King at the IFS. Participants received a diet journal to document all dietary intakes during the 8-week study. All diet journals were collected at the end of the study and reviewed using ESHA processor by a graduate student and/or volunteer nutritional science major student. Groups were closely monitored to ensure that they all received equal amounts of fat in their diet according to AHA guidelines. All groups received the same education.

Participants had their pistachios delivered twice by graduate students. The first delivery included approximately half the supply of pistachios; the second delivery included the remaining supply. Participants also received phone calls from graduate students every other day. The calls focused on encouraging diet adherence by collecting a one day food recall. Participants were asked to recollect what they had to eat the day prior as well as whether they ate their pistachios and how much. The information collected was documented by the participant in their food journal and by the graduate student. The food recalls were analyzed using ESHA processor and compared to previous records to measure adherence to the calorie controlled diet and to monitor changes. If a participant was not abiding by calorie restrictions and/or guidelines, then the graduate student reinstated the participant expectations. If a participant failed to follow study expectations (avoiding all other nuts, tree nuts, seeds or treatment) for more than 3 consecutive days their results were not included in the study.

\section{$\underline{\text { Measurements }}$}

In order to access glucose levels, participants were instructed to fast overnight prior to each health exam. The required fasting length for the lipid panel was 8-10 hours. The study analyzed and evaluated changes in: TC, HDL, VLDL, 
Direct LDL, TG, FPG levels, Resting Heart Rate (RHR) and BP. In addition, the study measured biomarkers of inflammation, hs-CRP. Blood was drawn by a phlebotomist and analyzed by Sierra Endocrine Laboratory an accredited laboratory. All measurements were conducted at commencement of the study and at the end. The lipid panel and FPG were analyzed using an ACE Alera Analyzer manufactured by Alfa Wasserman according to CDC guidelines available through the CDC website (CDC-NHLBI lipid standardization). Hs-CRP was measured through a solid-phase, chemiluminescent immunometric assay also known as an antigen antibody reaction using Immulite analyzer manufactured by Seiman's diagnostic (refer to Appendix F).

BP and RHR measurements were also conducted during each blood draw, therefore a total of two times for each participant. BP and RHR were taken using an automatic inflation blood pressure monitor. After the participant had been sitting down in the exam room for 10 minutes they had their BP measurement. During the 10 minute gap participants refrained from doing any type of activity that may affect their BP. Prior to taking their BP a series of questions were asked (refer to Appendix G). Life stressors were noted, for example psychological state, arthritis, and pain. The questions pertained to any events or medications that may have altered their BP significantly, observations were noted. The observations were noted by graduate students and or trained undergraduate student volunteers. Trained student volunteers assisted with BP measurements and RMR readings (refer to Appendix H for BP and RHR protocols). All data were collected and documented for evaluation on SPSS software. 
Statistical Analysis and Interpretation

Data was analyzed using the latest edition of Microsoft Excel software 2007. Initially each group was assessed separately to determine mean, Standard deviation (stdev) from the mean and the Coefficient of variation (CV). In addition, each individual was assessed to determine difference between baseline levels and end of the study levels. The differences were assessed by a simple t-test two tailed with equal variance to determine whether a difference was observed between treatment and control, $t$ and $p$ values listed.

Diet was analyzed to determine mean intakes during 8-week period then compared to calculated RMR w/AF through a one tailed, paired t-test analysis. In addition, a comparison was made between the Holiday events (Nov $26^{\text {th }}$, Dec $24^{\text {th }}$, Dec $25^{\text {th }}$ and Dec $31^{\text {st }}$ ) and mean food intakes to determine if the holidays had an effect on food intake through a two tailed, paired t-test with equal variance.

Data from each participant was batched for analyses. Upon completion of the analysis, data was interpreted for statistical significance. A difference of $\alpha \leq$ 0.05 , is considered statistically significant. 
Chapter 4

\section{RESULTS}

\section{Lipid Panel}

The results of the study for the lipid panel are listed in Table 3. No statistical difference was detected for the following variables: TC $(\mathrm{p}=0.919)$, VLDL ( $p=0.962)$, I-LDL ( $p=0.884)$, TG ( $p=0.816), D-L D L ~(p=0.827)$, and HDL $(\mathrm{p}=0.713$ ). Levels in the Pistachio group for the following variables decreased from baseline to end of the study including: TC ( $\Delta=8.2)$, VLDL ( $\Delta=3.44)$, I-LDL $(\Delta=4.0), \mathrm{TG}(\Delta=17.2)$, and $\operatorname{HDL}(\Delta=0.8)$; these changes were not statistically significant. Levels in the Control group for the following variables decreased from baseline to end of the study including: TC ( $\Delta=7.2)$, VLDL ( $\Delta=3.54)$, I-LDL $(\Delta=2.4)$. The pistachio group D-LDL increased by $2.0 \mathrm{mg} / \mathrm{dL}$, however the increase was not statistically significant. A similar increase in D-LDL was also observed in the Control group $4.6 \mathrm{mg} / \mathrm{dL}$, which was not significant.

\section{Blood Pressure, Resting Metabolic Rate, FPG, and CRP}

The results of the study for BP, RMR, FPG, and CRP are listed in Table 4. No statistical difference was detected for BP sys $(\mathrm{p}=0.187)$, BP dia $(\mathrm{p}=0.263)$, RHR ( $p=.910)$, FPG ( $p=0.196)$, and CRP ( $p=0.921)$. In addition, no difference was detected for within group analysis; that is with each group no difference was detected between pre and post data. The levels in the Pistachio group for the following variables decreased from baseline to end of the study levels: BP systolic $(\Delta=1.4)$, BP diastolic $(\Delta=1.0), \operatorname{FPG}(\Delta=50.0)$, and CRP $(\Delta=0.112)$. These differences were not statistically significant. The levels in the Control group for the following variables decreased from baseline to end of the study levels: BP 


\section{Table 3}

Serum lipid effects of pistachios in subjects with MetS

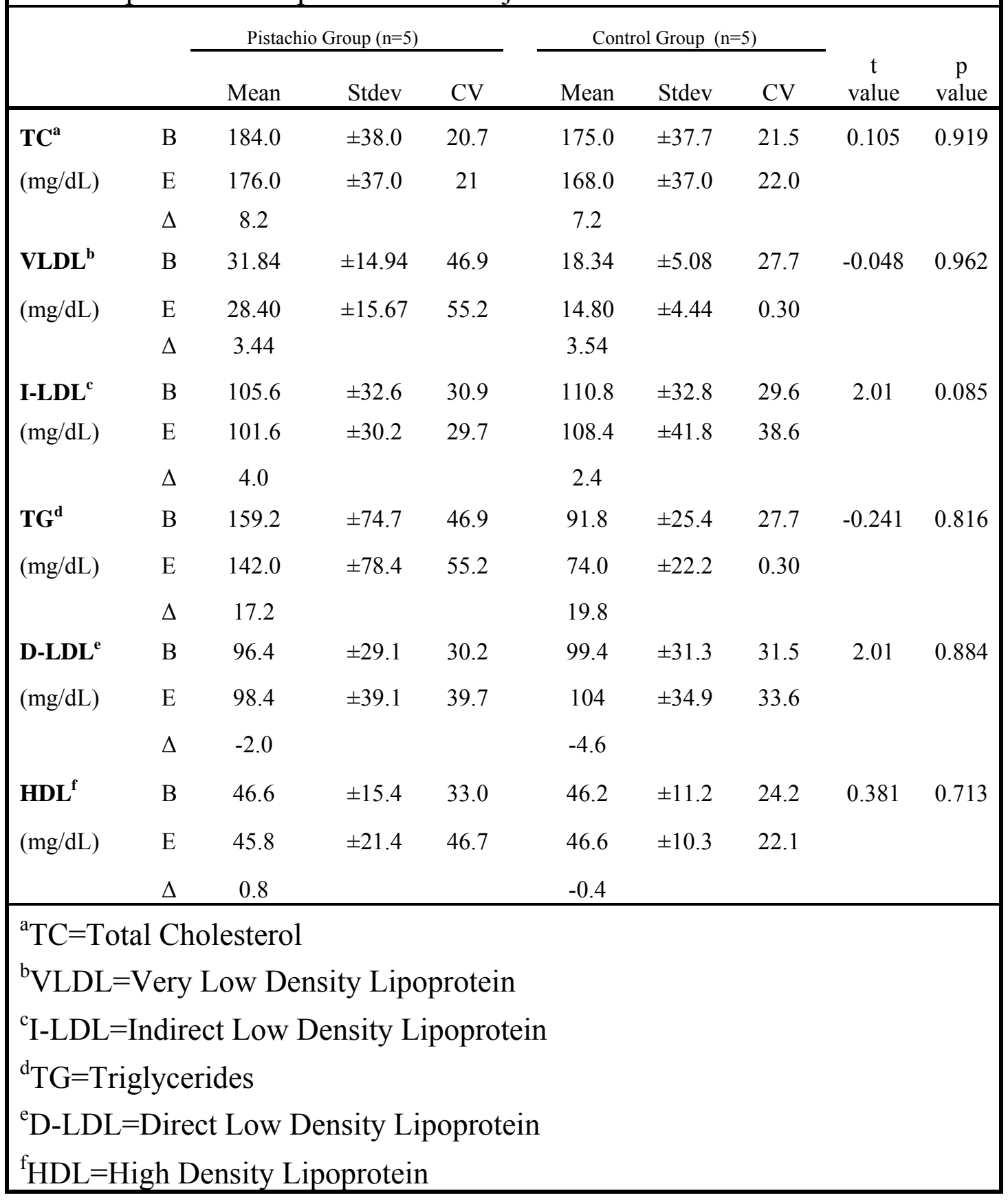


Table 4.

Blood pressure, resting heart rate, fasting plasma glucose and and C-reactive protein effects of pistachios on subjects with MetS

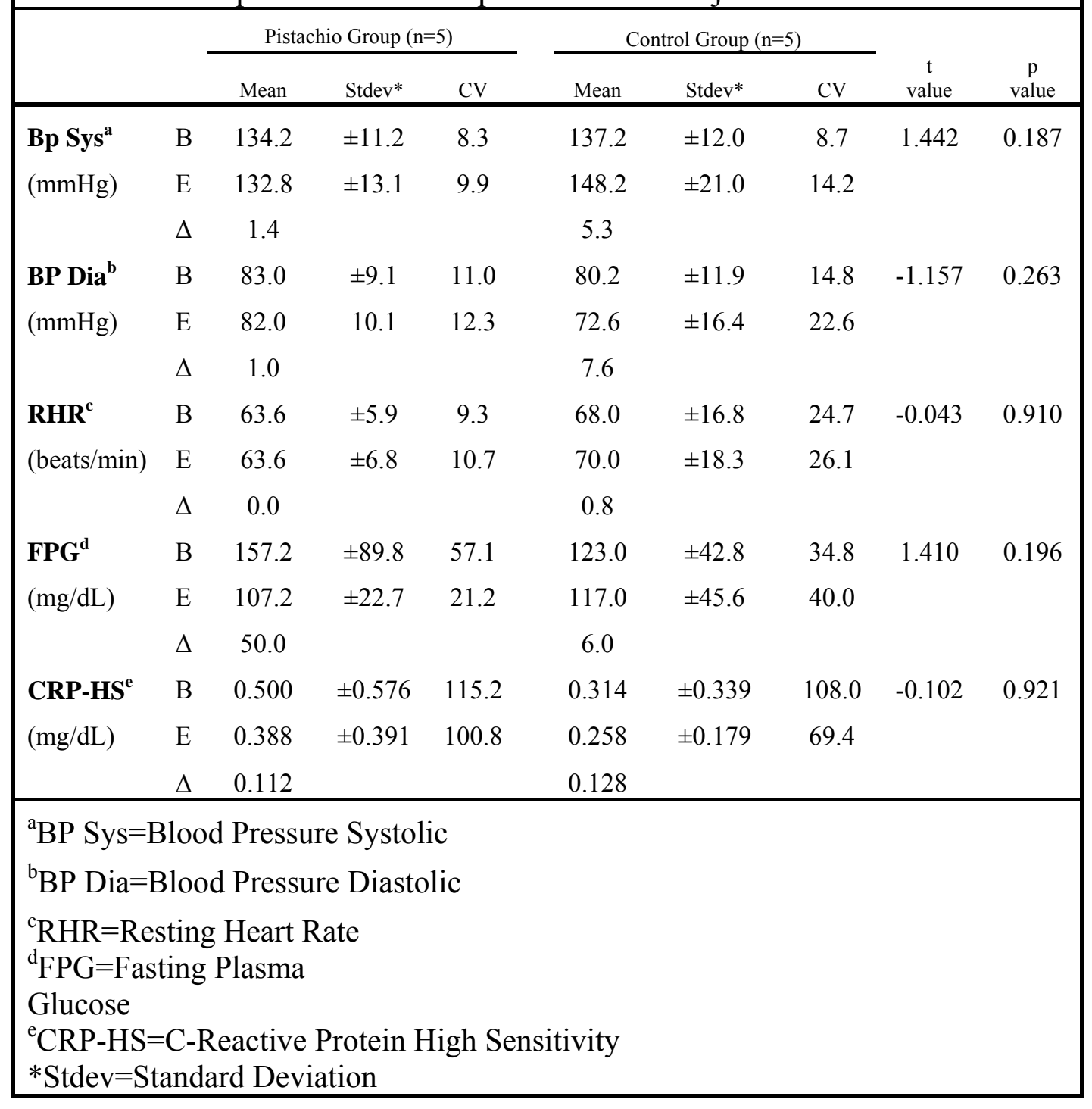


systolic $(\Delta=5.3)$, BP diastolic $(\Delta=7.6)$, FPG $(\Delta=6.0)$, and CRP $(\Delta=0.128)$. These differences were not statistically significant.

\section{Dietary Intake}

The results of the study showed that the participants in both the pistachio and the control group did not adhere to their calorie controlled diet expectations. Although some participants stayed within their controlled calorie guidelines, the overall difference between the food reports and the assigned calorie diet was significantly different $(\mathrm{p}=0.030)$ (refer to Table 5 ). When comparing the Control group and the Pistachio group individually to find out whether calorie intake varied between groups, no significant difference was detected $(\mathrm{p} \geq 0.05)$.

\section{Table 5}

Analysis of food dairies of subjects with MetS and resting metabolic rates given in kcal

\begin{tabular}{|c|c|c|c|c|c|c|}
\hline & \multicolumn{2}{|c|}{ Pistachio Group } & \multicolumn{2}{|c|}{ Control Group } & \multirow[b]{2}{*}{$\mathrm{t}^{*}$} & \multirow[b]{2}{*}{$\mathrm{p}$} \\
\hline & $(n=5)$ & $\mathrm{CV}$ & $(n=5)$ & $\mathrm{CV}$ & & \\
\hline $\begin{array}{l}\text { Mean 24hr Food } \\
\text { Intakes }^{\mathrm{a}}\end{array}$ & $2120 \pm 499^{d}$ & 23.5 & $1753 \pm 500^{d}$ & 28.8 & -2.16 & 0.030 \\
\hline $\begin{array}{l}\text { Mean 24hr Food Intakes } \\
\text { (Holidays) }^{\mathbf{b}}\end{array}$ & $2188 \pm 582^{d}$ & 27.0 & $2065 \pm 772^{d}$ & 37.4 & 1.75 & 0.054 \\
\hline $\begin{array}{l}\text { RMR } \\
\mathrm{W} / \mathrm{AF}^{\mathrm{c}} \text { mean intakes }\end{array}$ & $2258 \pm 200^{\mathrm{e}}$ & & $2302 \pm 200^{\mathrm{e}}$ & & & \\
\hline $\begin{array}{l}{ }^{\mathrm{a}} \text { Food report calculation } \\
{ }^{\mathrm{b}} \text { Holidays: } 11 / 26 \text { (Thank } \\
\text { 12/31 (New Year's Eve) } \\
{ }^{\mathrm{c}} \mathrm{RMR} \text { w/AF=Resting M } \\
{ }^{\mathrm{d}} \text { Standard Deviation of } \\
{ }^{\mathrm{e}} \text { Subjects allowed to dev } \\
{ }^{*} \mathrm{t} \text { value between Mean } 2\end{array}$ & $\begin{array}{l}\text { ived on food } \\
\text { fiving), } 12 / 2 \\
\text { abolic Rate } \\
\text { te from calo } \\
\text { ar food intak }\end{array}$ & $\begin{array}{l}\text { es and } \\
25 \text { (Ch } \\
\text { ctivity } \\
\text { RMe bas } \\
\text { RMR }\end{array}$ & $\begin{array}{l}\text { journals } \\
\text { as Eve, Day } \\
\text { tor }\end{array}$ & \pm 200 & Kcal & \\
\hline
\end{tabular}




\section{Chapter 5}

\section{DISCUSSION}

\section{Examination of Results}

In this study the effects of pistachios were evaluated along with a calorie controlled diet on subjects with MetS. This study was unable to detect any statistically significant differences in any of the measured variables: the lipid panel (Table 3), BP, RMR, FPG, and CRP ( $\mathrm{p} \geq 0.05$ ) (Table 4). Only one blood sample was collected and analyzed. Duplicate assessment and sampling of the variables measured would increase the confidence of the lab results. Although no statistical difference was detected, the pistachio diet may have elicited an effect that went undetected. It is possible that I have a type one error hypothesis. The pistachio diet may have had an effect however it was not detected due to the small number of participants. For example, FPG levels decreased in the treatment group by 50 $\mathrm{mg} / \mathrm{dL}$, where as in the control group FPG levels decreased $6 \mathrm{mg} / \mathrm{dL}$, although that difference was present it was not statistically significant. It is possible that the difference may have not been detected due to the small sample population. One of the most challenging parts of the study was the recruitment process. Participants declined to participate due to the inconvenience of travel and time.

Along with the pistachio treatment, a calorie controlled diet was used. The calorie controlled diet did not elicit a statistically significant effect on any of the measured variables: the lipid panel, BP, RMR, FPG, and CRP ( $p \geq 0.05$ ). We selected a calorie controlled diet to help keep both the control group and the pistachio group under similar conditions. In addition, we selected a calorie controlled diet to help maintain the subject's weight. The calorie controlled diet is flexible for the subjects in that it allows them to choose what they eat. The mean 
calorie (RMR) calculation of the Pistachio and Control groups, are listed accordingly $2258 \mathrm{kcal}$ and $2302 \mathrm{kcal}$. Based on our analysis participants in both groups did not adhere to calorie control guidelines $(\mathrm{p}=0.030)$ (refer to table 5).

There are several explanations as to why participants did not follow the calorie controlled diet. One explanation is inaccurate food recalls. Some participants might have struggled with the quantitative assessment of the food reports. A Calorie King booklet was provided to participants to assist with food recalls and calorie counting. In addition, it is common to underreport on food recalls (47). Of the 10 participants that completed the study, 9 participants reported consuming fewer calories than what was calculated for them using the RMR with Activity Factor. Refer to Table 5 for mean food intakes and mean indirect calorimeter results (RMR w/AF) (47).

The study was conducted during the holiday season from November 16,' 2009 through January 10, 2010. The calorie intake for the holidays: Christmas, Thanksgiving and New Year's Eve (refer to Table 5) remained fairly close to the entire 8-week mean calorie intakes. The data collected from the food journals may contain inaccurate information. Research has shown that the use of food journals as a dietary intervention can be faulty $(47,48)$. Overweight subjects tend to underreport on food recalls (47). All but 4 of the 10 subjects that participated in and completed the study were within the obese range ( $\left.\geq 30 \mathrm{~kg} / \mathrm{m}^{2} \mathrm{BMI}\right)$ (refer to Table 2). The remaining 4 subjects were within the overweight range and at risk for being obese $\left(25.0 \mathrm{~kg} / \mathrm{m}^{2}\right.$ and $29.9 \mathrm{~kg} / \mathrm{m}^{2)}$. I am unable to fairly assess the effect the holiday season might have had on the participants and the results, since the food reports might contain inaccurate information $(47,48)$.

Using subjects with MetS can be challenging. Most, if not all of the participants were on pharmacotherapy. Two individuals, one from the control and 
another from the treatment group changed their medication regimen during the course of the study. In addition, one participant from the control group had a myocardial infarction and was withdrawn from the study.

\section{Future Applications and Conclusions}

This is the only study to examine both pistachios and participants diagnosed with MetS. In addition, it is among the few studies to include MetS as a subject criterion. This study will assist with future research on MetS by serving as a reference. The study may have yielded different results if changes were made in the following ways: experimental design, using different subject criteria and a larger sample size. Changing the study's subject criteria to include only healthy subjects would help minimize error due to pharmacotherapy. It is possible that the effects of the pistachios were masked by the subject's pharmacotherapy. Although no effects from the pistachios were detected in this study it is important to note that none of the metabolic indicators changed unfavorably during the study.

We were unable to demonstrate that pistachios affect the metabolic profile of individuals with MetS favorably. However, we did show that pistachios do not have a negative effect on the health profile of individuals with MetS. In addition, we found that the calorie controlled diet was not followed and/or food intake was not accurately reported. Further research investigating methods of dietary collection, and ways of increasing the effectiveness of calorie controlled diets needs to be further explored. This study will serve as a useful reference for future studies that look at MetS, pistachios and calorie controlled diets. 
REFERENCES 


\section{REFERENCES}

1. Lorgeril M, Salen P, Martin J L, Monjaud I, Delaye J, and Mamelle N. Mediterranean diet, traditional risk factors, and the rate of cardiovascular complications after myocardial infarction : Final Report of the Lyon Diet Heart Study. American Heart Association. Circulation. 1999;99;779-785.

2. Thom T, Haase N, Rosamond. American Heart Association Statistics Committee and Stroke Statistics Subcommittee, Heart disease and stroke statistics - 2006 update: a report from the American Heart Association Statistics Committee and Stroke Statistics Subcommittee. Circulation. 2006; 113:85-151.

3. Fraser GE, Sabaté J, Beeson WL, Strahan TM. A possible protective effect of nut consumption on risk of coronary heart disease: The Adventist Health Study. Arch Intern Med. 1992;152:1416-1424.

4. Ford E, Giles W, Mokdad AH, Increasing prevalence of the Metabolic Syndrome among U.S. Adults. Diabetes Care. 2004; 27: 2444-2449.

5. Lorenzo C, Williams K, Hunt KJ, Haffner SM. The National Cholesterol Education Program-Adult Treatment Panel III, International Diabetes Federation, and World Health Organization definitions of the Metabolic Syndrome as predictors of incident Cardiovascular Disease and Diabetes. Diabetes Care. 2007;30: 8-13.

6. Grundy S, M., Brewer BH, Cleeman JI, Smith SC, Lenfant C. For the conference participants. definition of Metabolic Syndrome: Report of the National Heart, Lung, and Blood Institute/American Heart Association conference on scientific issues related to definition. Circulation. 2004;109: 433-438.

7. American Diabetes Association: Economic costs of diabetes in the U.S. in 2007. Diabetes Care. 2008;31:596-615.

8. Grundy SM. Comparison of monounsaturated fatty acids and carbohydrates for lowering plasma cholesterol. $N$ Engl J Med. 1986;314:745-748. 
9. Pelkman C, Fishell V, Maddox D, Pearson T, Mauger D, Kris-Etherton P. Effects on moderate-fat (from monounsaturated fat) and low-fat weight loss diets on the serum lipid profile in overweight and obese men and women. Am J Clin Nutr. 2004;79:204-212.

10. Berry EM, Eisenberg S, Harahtz D. Effects of diets rich in monounsaturated fatty acids on plasma lipoproteins - The Jerusalem Nutrition Study: high MUFAs vs high PUFAs. Am J Clin Nutr. 1991;53:899-907.

11. Hu FB, Stampfer MJ, Manson JE. Frequent nut consumption and risk of coronary heart disease in women: Prospective Cohort Study. BMJ. 1998;317:1341-1345.

12. Peterson J, Oosthuzien W, Jerling J. A systemic review of the effects of Nuts on Blood Lipid Profiles in Humans. J of Nutr. 2005;135:2082-2089.

13. Sheridan M, Copper J, Erario M, Chefitz C. Pistachio nut consumption and serum lipid levels. J Am Coll Nutr. 2007;2:141-148.

14. Kushi LH, Lew RA, Stare FJ, Ellison CR, Lozy M, Bourke G, Daly L, Graham I, Hickey N, Mulcahy R: Diet and 20-year mortality from coronary heart disease: The Ireland-Boston Diet- Heart study. N Engl J Med. 1985;312:811818.

15. Riccardi G, Giacco R, Rivellese AA. Dietary fat, insulin sensitivity and the metabolic syndrome. Clin Nutr. 2004;23:447-456.

16. Kennedy A, Martinez K, Chuang CC, LaPoint K, McIntosh M.Saturated fatty acid-mediated inflammation and insulin resistance in adipose tissue: mechanisms of action and implications. J of Nutr. 2009;139:1-4.

17. Spiller GA, Jenkins DJA, Bosello O, Gates JE, Cragen LN, Bruce B. Nuts and plasma lipids: an almond-based diet lowers LDL-C while preserving HDL-C. J Am Coll Nutr. 1998;17:285-290.

18. Kornsteiner M, Wagner KH, Elmadfa I. Tocopherols and total phenolics in 10 different nut types. Food Chemistry. 2006;98:381-387.

19. Ridker P. Clinical application of C-Reactive Protein for cardiovascular disease detection and prevention. Circulation. 2003;107:363-369.

20. Santos A, Lopes C, Guimares J, Barros H. Central obesity as a major determinant of increased high sensitivity C- Reactive Protein in Metabolic Syndrome. Intern J of Obesity. 2005;20:1452-1456. 
21. Jenkins DJ, Cyril KW, Marchie A, Josse A, Nguyen TH, Faulkner DA, Lapsley KG, Blumberg J. Almonds reduce biomarkers of lipid peroxidation in older hyperlipidemic subjects. J of Nutr. 2008;138: 908-913.

22. De la Puerta R, Marquez-Martin A, Fernandez-Arche A, Ruiz-Gutierrez V. Influence of dietary fat on oxidative stress and inflammation in murine macrophages. Nutrition. 2009; 5 :548-554.

23. USDA Nutrient Database for Standard Reference:USDA ;2009 : At http://www.nal.usda.gov/fnic/foodcomp/search/. Accessed on September 01, 2009.

24. Ford ES. Risks for all cause mortality, cardiovascular disease, and diabetes associated with the Metabolic Syndrome: A summary of the evidence. Diabetes Care. 2007;28:1769-1778.

25. Jenkins DJ, Lapsley A, Spiller GA, Connelly PW, Qian W, Haight J, Faulkner E, Vidgen KG, Kendall CW, Marchie A, Parker PW. Dose Response of almonds on Coronary Heart Disease risk factors: blood lipids, oxidized lowdensity lipoproteins, lipoprotein(a), homocysteine, and pulmonary nitric oxide: A randomized, controlled, crossover trial. Circulation. 2002;106:1327-1332.

26. Nutrition Insights: Are all food pyramids created equal?: USDA; 1997: http://www.cnpp.usda.gov/...s/NutritionInsights/insight2.pdf . Accessed August 31, 2009.

27. Tortosa, A. Bes-Rastrollo M, Sanchez-Villegas A, Basterra-Gortari FJ, NunezCordoba JM, Gonzalez MM. Mediterranean diet inversely associated with the incidence of Metabolic Syndrome: The SUN prospective cohort. Diabetes Care. 2007;30:2957-2959.

28. Due A, Larsen TM, Hermansen K, Stender S, Holst J, Toubro S, Martinussen $\mathrm{T}$, Astrup A. Comparison of the effects on insulin resistance and glucose tolerance of 6-month high-monounsaturated-fat, low-fat, and control diets. Am J Clin Nutr. 2008;87: 855-862.

29. Garg A, Bonanome A, Grundy SM, Zhang Z-J, Unger RH. Comparison of a high-carbohydrate diet with a high-monounsaturated fat diet in patients with non-insulin-dependent diabetes mellitus. $N$ Engl J Med. 1988;319:829-934.

30. Sabate J. Nut consumption and body weight. Am J Clin Nutr. 2003;78: 647650. 
31. Edwards K, Kwaw I, Matud J, Kurtz I. Effect of pistachio nuts on serum lipid levels in patients with moderate hypercholesterolemia. J Am Coll Nutr. 1999;18: 229-232.

32. Sabate J, Corodero Z, Siapco G, Torabian S, Haddad E. Does regular walnut consumption lead to weight gain? British J of Nutrition. 2005; 94:859-864.

33. Fraser GE, Bennett HW, Jaceldo KB, Sabate J. Effect on body weight of a free 76 kilojoule (320 Calorie) Daily Supplement of Almonds for Six Months. $J$ Am Coll Nutr. 2002;21:275-283.

34. Gebauer SK, West SG, Kay CD, Alaupovic P, Bagshaw D, Kris-Etherton P. Effects of pistachios on cardiovascular disease risk factors and potential mechanisms of action: a dose-response study. Am J Clin Nutr. 2008;88:651659.

35. Spiller GA, Miller A, Olivera K, Reynolds J, Miller B, Morse SJ, Dewell A, Farquhar JW. Effects of plant-based diets high in raw or roasted almonds, or roasted almond butter on serum lipoproteins in humans. J Am Coll Nutr. 2003;22:195-200.

36. Emilio R, Nunez I, Perez-Heras A, Merce S, Gilabert R, Casals E, Deulofeu R. A Walnut diet improves endothelial function in hypercholesterolemic subjects: A randomized crossover trial. Circulation. 2004;109:1609-1614.

37. Mukuddem-Petersen J, Stonehouse W, Jerling JC, Hanekom S, White Z. Effects of a high walnut and high cashew nut diet on selected markers of the metabolic syndrome: a controlled feeding trial." The British J of Nutrition. 2007;97:1144-1153.

38. Gordon DJ, Probstfield JL, Garrison RJ, Neaton JD, Castelli WP, Knoke JD, Jacobs DR, Bangdiwala S, Tyroler HA. High-density lipoprotein cholesterol and cardiovascular disease. Four prospective American studies. Circulation. 1989;79: 8-15.

39. Kinosian B, Glick H, Garland G. Cholesterol and Coronary Heart Disease: predicting risks by levels and ratios. Ann Intern Med. 1994;121:641-647.

40. Wu X, Beecher GR, Holden JM, Haytowitz DB, Gebhardt SE, Prior RL. Lipophilic and hydrophilic antioxidant capacities of common foods in the United States. Journal of Agricultural and Food Chemistry. 2004;52(12), 4026-4037. 
41. Houston MC, Harper KJ. Potassium, Magnesium, and calcium: Their role in both the cause and treatment of hypertension. Journal of Clinical Hypertension. 2008;10:2-11.

42. Appel LJ, Moore TJ, Obarzanek E, Vollmer WM, Svetkey LP, Sacks FM, Bray GA, Vogt TM, Cutler JA, Windhauser MM, Lin PH, Karanja N. A clinical trial of the effects of dietary patterns on blood pressure. DASH Collaborative Research Group. N Engl J Med. 1997;336: 1117-1124.

43. Aksoy N, Aksoy M, Bagci C, Gergerlioglu HS, Celik H, Herken E, Yaman A, Tarakcioglu M, Soydinc S, Sari I, Davutoglu V. Pistachio intake increases high density lipoprotein levels and inhibits low density lipoprotein oxidation in rats. Tohoku. J. Exp. Med. 2007;212:43-48.

44. Berk BC, Weintraub WS, Alexander RW. Elevation of C-reactive protein in 'active' coronary artery disease. Am J Cardiol. 1990;65:168 -172.

45. Santos A, Lopes C, Guimares J, Barros H. Central obesity as a major determinant of increased high sensitivity C- Reactive Protein in Metabolic Syndrome. International J of Obesity. 2005;20:1452-1456.

46. Kritchevsky SB, Bush AJ, Pahor M, Gross MD. Serum carotenoids and markers of inflammation in nonsmokers. American Journal of Epidemiol. 2000;152:1065-1071.

47. Myers RJ, Klesges RC, Eck LH, Hanson CL, Klem ML. Accuracy of selfreports of food intake in obese and normal-weight individuals: effects of obesity on self-reports of dietary intake in adult females. Am J Clin Nutr. 1988;48: 1248-1251.

48. Zepeda L, Deal D. Think before you eat: photographic food diaries as intervention tools to change dietary decision making and attitudes. International Journal of Consumer Studies. 2008;32:692-698. 
APPENDICES 
APPENDIX A

FLYER TO RECRUIT 


\section{Interested in Participating in a Pistachio Heart Healthy Research Project for Fresno State?}

Looking for individuals diagnosed with chronic health conditions such as but not limited to: diabetes and hypertension, to participate in our 20 week heart healthy study that will begin May 2009 conducted by California State UniversityFresno Food Science and Nutrition Department.

Those selected to participate will receive free pistachios and dietary counseling.

\section{Expectations:}

Participants will have to eat 3 ounces of pistachios daily for 8 weeks and completely

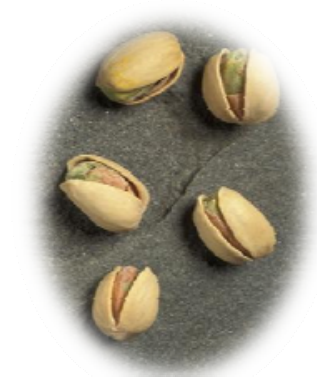
avoid all other nuts (including peanuts). Study includes:

Nutrition counseling by Registered Dietitian. Pistachios and counseling will be supplied to participants at no cost.

\section{Phone \# (559) 278-5621}


APPENDIX B

LETTER TO RECRUIT 
July 15,2009

Dear Potential Research Participant:

Currently, we are underway with an exciting research study at California State University, Fresno. This study involves looking at the effects of eating $1.5 \mathrm{oz}$ and $3.0 \mathrm{oz}$ 's of pistachios daily for eight weeks. We will be looking at the pistachio's effects on weight, metabolic rate, blood pressure, and the lipid panel and waist circumference. Our team includes Dr. Lisa Herzig, lead investigator, Michelle Carrick, RD and Mary Perez, Fresno State nutrition graduate students.

We are looking for participants that may be interested in taking part in our study. The criteria for participation include a single diagnosis of Type 2 diabetes mellitus, polycystic ovarian syndrome, metabolic syndrome, hypertension or others to be determined. This eight week study will include selection for a particular group that may or may not include consuming a certain prescribed dose of pistachios. Those selected will receive free pistachios and nutrition counseling by a registered dietitian.

If you are selected to participate in our study, you will have to ingest pistachios for eight weeks, avoid all other nuts during this time period and have certain blood work, blood pressure, and other measurements conducted both pre and post study. The other measurement tests include a resting metabolic rate test, waist circumference, blood pressure, height, weight and resting heart rate. These will all be provided at no extra charge to you as the participant.

If you are interested in participating in our study, or have any additional questions, please contact us by calling:

(559) 278-5621 (leave a message)

or emailing:

csufpistachiostudy@gmail.com

We look forward to hearing from you.

Sincerely, Lisa Herzig, PhD, RD 
APPENDIX C

INFORMATION SESSION AGENDA 


\section{Informational Session Agenda (IFS)}

- Sign in

- Introduction of the Team: Lisa Herzig R.D., Michelle Carrick R.D., Mary Perez

- Introduction of the Study: Pistachio Health Study

- Participant Expectations: Diet Adherence, Accurate Food Recalls, Attendance

- Participant Incentives: Free Pistachios, Free Dietary Counseling and free Health Assessment

- Disclosure and Agreement (signed consent form)

- Confidentiality

- Timeline (duration of study): Important Dates September $1^{\text {st }}$ Start Date, Nutrition

- Education dates

- Questions 


\section{APPENDIX D}

INITIAL DEMOGRAPHIC QUESTIONNAIRE 
Demographic Questionnaire

Gender: $\quad \mathrm{M} \quad$ or $\mathrm{F}$

Date of Birth:

Ethinicity:

- Caucasian/Non-hispanic

○ Mexican American/Hispanic

- African American

O Other specify

Physical activity level:

- Exercise 4 times per week or more at least $30 \mathrm{~min}$

- Exercise 2 times per week or more at least $30 \mathrm{~min}$

- Do not exercise regularly

Supplements:

- Multi-vitamins used daily for example: one a day, centrium, potassium, fish oil, fatty acid and B12 etc

- Multi-vitamins used more then once per week

○ Do not take multi-vitamins

If so, specify type of supplement:

Alcohol:

○ 1 or more drinks per day

○ 2 or more drink per week

- 1 or 2 drinks per week

○ Only on occasion less than once per week

Smoking:

○ Yes

○ No

If so, how often:

Referring clinic:

- Sierra Endocrine

- Cardiovascular Consultants

- Dr. Norwoods 
APPENDIX E

FINAL QUESTIONNAIRE 
Please indicate whether the following have changed during the 8 week study.

Physical activity level:

Remained the same___. If not indicate the following:

- Exercise 4 times per week or more at least 30 min

- Exercise 2 times per week or more at least $30 \mathrm{~min}$

- Do not exercise regularly

Supplements:

Remained the same___. If not indicate the following:

- Supplements used daily for example: one a day, centrium, potassium, fish oil, fatty acid and B12 etc.

- Supplements used more than once per week

○ Do not take multi-vitamins

If so, specify type of supplement:

\section{Alcohol:}

Remained the same . If not indicate the following:

- 1 or more drinks per day

- 2 or more drink per week

- 1 or 2 drinks per week

- Only on occasion less than once per week

Smoking:

Remained the same . If not indicate the following:

○ Yes

○ No If so, how often:

Medications:

Remained the same___ If not please include description of changes (note changes in type of medication, frequency and dosage. 


\section{APPENDIX F}

PROTOCOL FOR BLOOD DRAW 


\section{Blood Draw Protocol:}

In order to access glucose levels, overnight fasting prior to each exam will occur. The fasting length is 10 to 12 hours to examine the lipid panel. Blood collection will occur a week prior or one week into the start of each diet and no later then a week after each diet phase ( 2 phases), therefore a total of four times for each subject.

\section{Participants:}

Instructed to come in the morning and skip breakfast time frame 6 am to 9 am.

\section{Phlebotomist:}

Blood collection will be conducted by a trained phlebotomist. Since the study depends on the voluntary return of participants over an extended period, the phlebotomist should make every effort to make the entire procedure as easy and painless as possible. The phlebotomist should remain calm and project a confident attitude even when faced with the most nervous or inquiring participant.

Total approximate time for each patient 15 to 20 minutes. For the patients not being seen at the sierra endocrine office $30 \mathrm{ml}$ of blood will be collected and sent to main lab site (sierra endocrine) by trained courier. The blood samples will be kept well insulated and cool according to normal guidelines established by courier. Each sample will be labeled with today's date and time, patient information: gender, date of birth and last name, first name. Results retrieved will be batched for analyses and recorded in patient's binder/ folder.

\section{Measurement:}

Blood analyzed for: total cholesterol, HDL, direct-LDL, triglycerides, hs-CRP and fasting glucose levels. Blood will be drawn by a phlebotomist and analyzed by Sierra Endocrine an accredited laboratory. The following measurements will be conducted at commencement of each diet and at the end of each diet that is during $8^{\text {th }}$ week. 
Protocol for Blood Pressure and Resting Heart Rate:

Blood Pressure (Bp) and Resting Heart Rate (RHR) measurements will also be conducted during each blood draw and half way into the study, therefore a total of three times for each phase. Each participant will undergo two phases the combined total measurement. Blood pressure (BP) will be taken using an automatic inflation blood pressure monitor.

\section{Patient:}

-Should refrain from smoking or ingesting caffeine 30 minutes prior to measurement. -Be seated quietly for at least 10 minutes magazine reading material may be provided. The estimated total time 15 minutes per participant. -Keep feet on the floor and arm supported at heart level.

\section{Graduate Student:}

-Always conduct Bp and RHR Measurements before blood draws. After each patient completes this measurement they will have their blood draw.

-Use appropriate cuff size for patient. The cuff bladder should encircle $80 \%$ of the cuff arm. An extra large cuff maybe needed.

-Prior to taking their BP patients will be asked a series of questions (refer to appendix A). Life stressors will be noted for example psychological state, arthritis, and pain. The questions pertain to any events or medications that may alter their Bp significantly, observations will be noted their patients folder.

\section{Procedure using automatic inflation blood pressure monitor:}

- $\quad$ Put the left arm through the cuff loop, making sure that the bottom edge of the cuff is approximately $1 / 2$ inch above the elbow. Pull the end of the cuff so that the entire cuff is evenly tightened around the arm with room for 1 finger between cuff and arm. Press the sewn hook material firmly against the pile side of the cuff. The cuff tubing should be positioned along the middle of the inside of the arm.

- Relax the arm and turn the palm upward. Locate the brachial artery by pressing with two fingers about 1 inch above the bend of the elbow on the inside of the left arm. Determine where the pulse can be felt most strongly. Make sure the green area of the cuff covers the brachial artery. 
- Press the On/Off button. Let the participant know that there may be a squeezing sensation as the cuff inflates. Be sure pressure valve is set to 200 . Advise the participant to remain still, without talking, throughout the test.

- Press the Start button after the Ready to Measure Symbol (a heart) appears next to a zero on the digital panel. If skin becomes pinched, immediately deflate the cuff bladder and readjust the cuff. When the measurement is complete, the monitor alternately displays blood pressure and pulse (RHR) on the digital panel and automatically deflates the cuff.

- If their $\mathrm{Bp}$ is significantly different $\mathrm{Bp} \geq 10 \mathrm{mmHg}$ participants will be asked to return in one week to retake measurement.

- If we continue to note an unusually high number $\mathrm{Bp} \geq 10 \mathrm{mmHg}$, and the participant has notified us that they recently took their Bp medication or coffee we will not include their data in results and justify the reason. Although we will not include their results we will allow the participant to continue to participate in the study.

(Blood pressure protocol by: tufts.edu/med/.../tnc-cdaar/protocols/Bloodpressure.doc) 
APPENDIX G

QUESTIONS DURING BLOOD PRESSURE MEASUREMENT 
Questions during Blood pressure measurement

1. How are you feeling today?

2. Anything unusual happen recently that might affect your current well being.

3. Any unusual change in you medication regimen?

4. Do you take blood pressure medication? If so, did you take your blood pressure medication today and when?

5. Did you drink for example: coffee, energy drink i.e. red bull and/or alcohol? If so, was it more then usual? How much?

6. Do you eat breakfast, if so what? 


\section{APPENDIX H}

PROTOCOL FOR BLOOD PRESSURE AND RESTING HEART RATE 
Protocol for Blood Pressure and Resting Heart Rate:

Blood Pressure (Bp) and Resting Heart Rate (RHR) measurements will also be conducted during each blood draw and half way into the study, therefore a total of three times for each phase. Each participant will undergo two phases the combined total measurement. Blood pressure (BP) will be taken using an automatic inflation blood pressure monitor (MODEL \#MARHEM711DLX).

\section{Patient:}

-Should refrain from smoking or ingesting caffeine 30 minutes prior to measurement. -Be seated quietly for at least 10 minutes magazine reading material may be provided. The estimated total time 15 minutes per participant. -Keep feet on the floor and arm supported at heart level.

\section{Graduate Student:}

-Always conduct Bp and RHR Measurements before blood draws. After each patient completes this measurement they will have their blood draw.

-Use appropriate cuff size for patient. The cuff bladder should encircle $80 \%$ of the cuff arm. An extra large cuff maybe needed.

-Prior to taking their BP patients will be asked a series of questions (refer to appendix A). Life stressors will be noted for example psychological state, arthritis, and pain. The questions pertain to any events or medications that may alter their Bp significantly, observations will be noted their patients folder.

\section{Procedure using automatic inflation blood pressure monitor:}

- $\quad$ Put the left arm through the cuff loop, making sure that the bottom edge of the cuff is approximately $1 / 2$ inch above the elbow. Pull the end of the cuff so that the entire cuff is evenly tightened around the arm with room for 1 finger between cuff and arm. Press the sewn hook material firmly against the pile side of the cuff. The cuff tubing should be positioned along the middle of the inside of the arm.

- Relax the arm and turn the palm upward. Locate the brachial artery by pressing with two fingers about 1 inch above the bend of the elbow on the inside of the left arm. Determine where the pulse can be felt most strongly. Make sure the green area of the cuff covers the brachial artery. 
- Press the On/Off button. Let the participant know that there may be a squeezing sensation as the cuff inflates. Be sure pressure valve is set to 200 . Advise the participant to remain still, without talking, throughout the test.

- Press the Start button after the Ready to Measure Symbol (a heart) appears next to a zero on the digital panel. If skin becomes pinched, immediately deflate the cuff bladder and readjust the cuff. When the measurement is complete, the monitor alternately displays blood pressure and pulse (RHR) on the digital panel and automatically deflates the cuff.

- If their $\mathrm{Bp}$ is significantly different $\mathrm{Bp} \geq 10 \mathrm{mmHg}$ participants will be asked to return in one week to retake measurement.

- If we continue to note an unusually high number $\mathrm{Bp} \geq 10 \mathrm{mmHg}$, and the participant has notified us that they recently took their Bp medication or coffee we will not include their data in results and justify the reason. Although we will not include their results we will allow the participant to continue to participate in the study.

(Blood pressure protocol by: tufts.edu/med/.../tnc-cdaar/protocols/Bloodpressure.doc) 


\section{California State University, Fresno}

\section{Non-Exclusive Distribution License}

(to make your thesis available electronically via the library's eCollections database)

By submitting this license, you (the author or copyright holder) grant to CSU, Fresno Digital Scholar the non-exclusive right to reproduce, translate (as defined in the next paragraph), and/or distribute your submission (including the abstract) worldwide in print and electronic format and in any medium, including but not limited to audio or video.

You agree that CSU, Fresno may, without changing the content, translate the submission to any medium or format for the purpose of preservation.

You also agree that the submission is your original work, and that you have the right to grant the rights contained in this license. You also represent that your submission does not, to the best of your knowledge, infringe upon anyone's copyright.

If the submission reproduces material for which you do not hold copyright and that would not be considered fair use outside the copyright law, you represent that you have obtained the unrestricted permission of the copyright owner to grant CSU, Fresno the rights required by this license, and that such third-party material is clearly identified and acknowledged within the text or content of the submission.

If the submission is based upon work that has been sponsored or supported by an agency or organization other than California State University, Fresno, you represent that you have fulfilled any right of review or other obligations required by such contract or agreement.

California State University, Fresno will clearly identify your name as the author or owner of the submission and will not make any alteration, other than as allowed by this license, to your submission. By typing your name and date in the fields below, you indicate your agreement to the terms of this distribution license.

\section{Mary Perez}

Type full name as it appears on submission

August 9, 2010

Date 